Article

\title{
SRG Inscription in Supramolecular Liquid Crystalline Polymer Film: Replacement of Mesogens
}

\author{
Shun Mitsui ${ }^{1}$, Shusaku Nagano ${ }^{2, *}$, Mitsuo Hara ${ }^{1}$ and Takahiro Seki ${ }^{1, *}$ \\ 1 Department of Molecular and Macromolecular Chemistry, Graduate School of Engineering, \\ Nagoya University, Furo-cho, Chikusa, Nagoya 464-8603, Japan; shiyun_mitsui@pref.aichi.lg.jp (S.M.); \\ mhara@apchem.nagoya-u.ac.jp (M.H.) \\ 2 Nagoya University Venture Business Laboratory, Furo-cho, Chikusa, Nagoya 464-8603, Japan \\ * Correspondence: snagano@apchem.nagoya-u.ac.jp (S.N.); tseki@apchem.nagoya-u.ac.jp (T.S.); \\ Tel.: +81-52-789-4668 (T.S.)
}

Academic Editor: Vladimir Chigrinov

Received: 16 January 2017; Accepted: 9 February 2017; Published: 11 February 2017

\begin{abstract}
The photoinduced surface relief formation via mass transfer upon irradiation with patterned light has long been a subject of extensive investigation. In azobenzene-containing liquid crystalline materials, UV light irradiation that generates the cis isomer leads to the liquid crystal to isotropic photochemical transition. Due to this phase change, efficiency of the mass transfer to generate a surface relief grating (SRG) becomes markedly greater. We have previously indicated that azobenzene-colored SRG-inscribed film can be bleached by removing a hydrogen-bonded azobenzene mesogen. However, this process largely reduces the height feature of the SRG corrugation. Herein, we propose an extended procedure where a colorless mesogen is filled successively after the removal of the azobenzene side chain. The process involves four stages: (i) SRG inscription in a hydrogen-bonded supramolecular azobenzene material; (ii) crosslinking (insolubilization) of the SRG film; (iii) removal of azobenzene mesogen by rinsing with a solvent, and (iv) stuffing the hollow film with a different mesogen. Although the final stuffing stage was insufficient at the present stage, this work demonstrates the possibility and validity of the strategy of mesogen replacement.
\end{abstract}

Keywords: azobenzene; liquid crystalline polymer; surface relief grating; hydrogen bonding

\section{Introduction}

The patterned photoirradiation onto azobenzene (Az)-functionalized polymer films at micrometer levels can induce mass transfers to form surface relief gratings (SRGs). The trans / cis photoisomerization cycle of $\mathrm{Az}$ under an interference laser illumination or patterned photo-illumination locally softens the Az polymers and induce lateral motions of the film materials. [1-7]. The resultant undulations correspond to the patterns of incident light modulations including both intensity [6,7] and polarization [1-4,8]. When side-chain liquid crystalline polymers (SCLCPs) are employed, the mass transfer becomes highly efficient. The photon dose for the completion of migration $[6,7,9-12]$ becomes approximately $10^{3}$-fold lower than that for widely reported amorphous polymers [1-3] and amorphous molecular materials $[13,14]$. This can be ascribed to the occurrence of isothermal liquid crystal (LC) to isotropic phase transition in the process of trans-to-cis photoisomerization [6,7,11,15-17]. The film material starts to move from the trans-rich regions to cis-rich ones, which is possibly initiated by the disparities of the viscosity and sharp gradient of surface tension at the boundary regions $[6,7,11,15]$.

The Az unit is essential for the photo-induced mass migration, but after the relief formation the existence of this strongly light absorbing chromophore can be a drawback for many optical applications. The removal of the strongly colored chromophore of $\mathrm{Az}$ is of particular advantage and demand for the applications to optical elements such as waveguide couplers and liquid crystal alignment layers. 
Therefore, detachment of Az moiety after the SRG formation without destroying the relief structure has been attempted by supramolecular strategy [18], heat [19], and photochemical [20] decompositions.

We have previously introduced an Az-containing SCLCP system [18] via the hydrogen-bonding framework proposed by Kato et al. [21-24] and demonstrated that the selective extraction (detachment) of $\mathrm{Az}$ units from the SRG inscribed film can be performed without alternation of the periodic features [18]. After the SRG is formed, the undulated film is first subjected to the chemical crosslinking, and the hydrogen-bonded Az side chain is successively detached by rinsing with a suitable solvent. This strategy actually worked in terms of bleaching the SRG film; however, the undulation height different was largely reduced to a one-fourth level after the removal of Az units [18]. In this context, we attempted to overcome this drawback by filling the contracted hollow SRG film with another mesogen that is transparent in visible light regions. We expected that the feature of the relief structure would be recovered in this procedure. The chemical structures of materials used in this study and their abbreviations are displayed in Scheme 1. To generate transparent SRG films at visible light wavelengths, the use of cinnamate-containing polymers provides simpler processes [8]. Nevertheless, this work newly demonstrates the strategy based on the chemical exchange of the constituents.
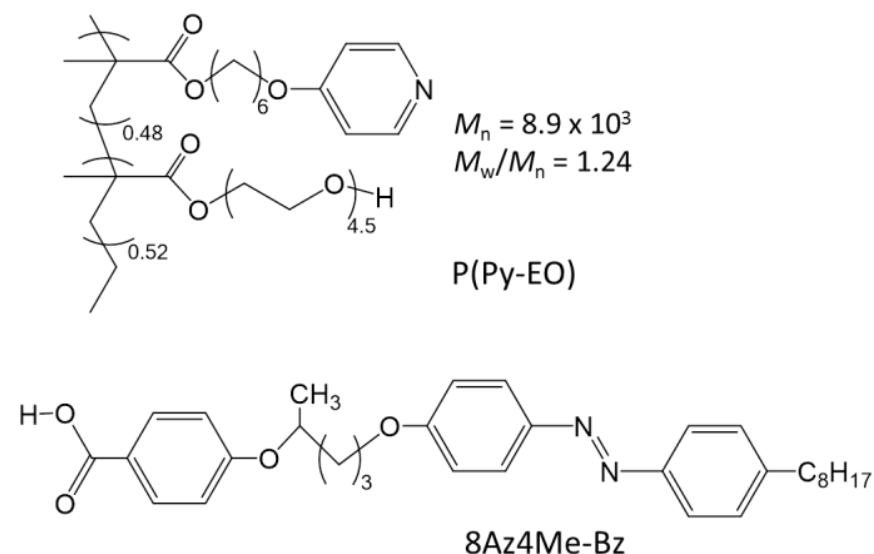

$8 \mathrm{Az} 4 \mathrm{Me}-\mathrm{Bz}$

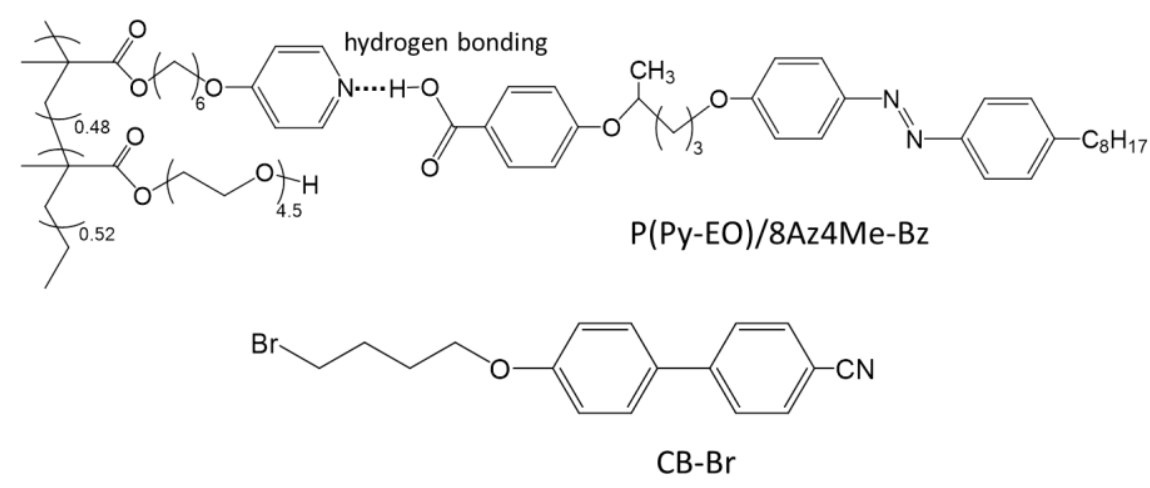

Scheme 1. Chemical structures and their abbreviations of materials used in this study.

\section{Results and Discussion}

\subsection{Characterizations of $P(P y-E O)-A z$}

The materials used in this study are indicated in Scheme 1. A random copolymer containing a pyridine-containing methacrylate and oligo(ethylene oxide) containing methacrylate ( $\mathrm{P}(\mathrm{Py}-\mathrm{EO})$ ) was synthesized using 2,2'-azobisisobutylonitril (AIBM) as the radical initiator. The feed ratio of pyridine monomer was 0.7 , and the resulting polymer possessed a copolymerization ratio of 0.48 for pyridine unit as revealed by ${ }^{1} \mathrm{H}-\mathrm{NMR}$ spectroscopy. Meanwhile, an Az derivative having a benzoic acid terminal (8Az4Me-Bz) was synthesized. The $\mathrm{P}(\mathrm{Py}-\mathrm{EO})$ polymer was mixed with $\mathrm{Az}$ in tetrahydrofuran (THF) 
at a 1:1 ratio with respect to the pyridine unit, and the solvent was then evaporated. This mixing procedure gave a hydrogen bonding complex $(\mathrm{P}(\mathrm{Py}-\mathrm{EO}) / 8 \mathrm{Az} 4 \mathrm{Me}-\mathrm{Bz})$ as also shown in Scheme 1 . In the molecular design of $8 \mathrm{Az} 4 \mathrm{Me}-\mathrm{Bz}$, the alkyl spacer between the $\mathrm{Az}$ unit and benzoic acid possessed a methyl branch, which prevented strong dimerization and stacking of Az-containing molecules in the hydrogen-bonded complex. This feature was favorable to effectively attain the hydrogen-bonded complex of $\mathrm{P}(\mathrm{Py}-\mathrm{EO}) / 8 \mathrm{Az} 4 \mathrm{Me}-\mathrm{Bz}$. As demonstrated below, the hydrogen bond complexation between $\mathrm{P}(\mathrm{Py}-\mathrm{EO})$ and $8 \mathrm{Az} 4 \mathrm{Me}-\mathrm{Bz}$ was confirmed and characterized by differential scanning calorimetry (DSC), FTIR spectroscopy, and X-ray scattering measurements.

Figure 1 shows the DSC curves for the host polymer (P(Py-EO), $8 \mathrm{Az} 4 \mathrm{Me}-\mathrm{Bz}$, and the complex (P(Py-EO)/8Az4Me-Bz). P(Py-EO) gave no appreciable change in the DSC curve. The 8Az4Me-Bz exhibited an exothermic peak at $133^{\circ} \mathrm{C}$ and two sharp endothermic peaks at $157^{\circ} \mathrm{C}$ and $166^{\circ} \mathrm{C}$ in the heating process. In contrast, $\mathrm{P}(\mathrm{Py}-\mathrm{EO}) / 8 \mathrm{Az} 4 \mathrm{Me}-\mathrm{Bz}$ exhibited small and broad and thermic peaks at $92{ }^{\circ} \mathrm{C}$ and $135^{\circ} \mathrm{C}$, and no peaks ascribed to the pure compound of $8 \mathrm{Az} 4 \mathrm{Me}-\mathrm{Bz}$ were observed at $157^{\circ} \mathrm{C}$ and $166^{\circ} \mathrm{C}$. Therefore, the thermal property of the complexed polymer was fully different. Polarizing optical microscopic observation (POM) indicated that this polymer exhibited a smectic $\mathrm{A}$ phase from $92{ }^{\circ} \mathrm{C}$ to $135^{\circ} \mathrm{C}$.

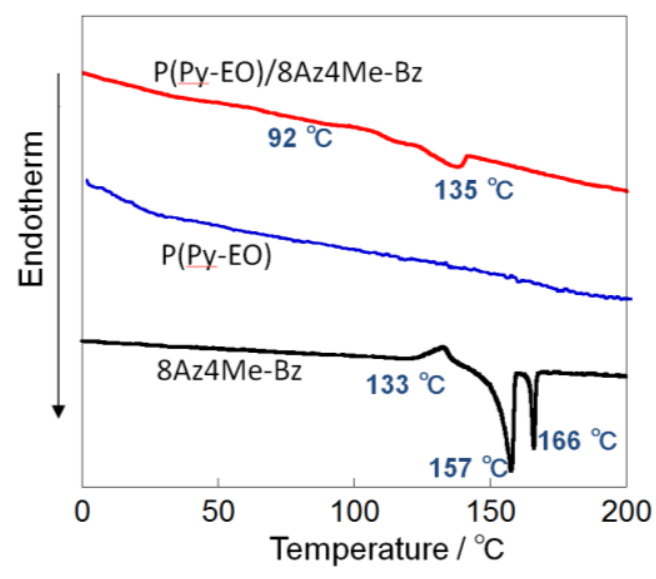

Figure 1. DSC profiles in the heating process.

Figure 2 displays FTIR spectra in $1600-3200 \mathrm{~cm}^{-1}$ (a) and $1400-1900 \mathrm{~cm}^{-1}$ (b) regions. For a $\mathrm{P}(\mathrm{Py}-\mathrm{EO}) / 8 \mathrm{Az} 4 \mathrm{Me}-\mathrm{Bz})$ film, characteristic bands were observed at 1917 and $2488 \mathrm{~cm}^{-1}$, which are indicative of the formation of the hydrogen band between carboxylic acid and pyridine [25]. These peaks were commonly observed at $25-150{ }^{\circ} \mathrm{C}(\mathrm{a})$, showing that the hydrogen bond was not cleaved in these temperature regions. A strong absorption band was observed at $1680 \mathrm{~cm}^{-1}$ assignable to the dimer formation $[21,22]$ between two benzoic acid groups of $8 \mathrm{Az} 4 \mathrm{Me}-\mathrm{Bz}$ molecules $(\mathrm{b}$, dotted curve). In contrast, $\mathrm{P}(\mathrm{Py}-\mathrm{EO}) / 8 \mathrm{Az} 4 \mathrm{Me}-\mathrm{Bz}$ indicated a smaller band at $1699 \mathrm{~cm}^{-1}$ instead of $1680 \mathrm{~cm}^{-1}$ at $25-150{ }^{\circ} \mathrm{C}[21,22]$. This also indicates the hydrogen bond formation between the benzoic acid of $8 \mathrm{Az} 4 \mathrm{Me}-\mathrm{Bz}$ and pyridine of $\mathrm{P}(\mathrm{Py}-\mathrm{EO})$. Therefore, the hydrogen bonding of $8 \mathrm{Az} 4 \mathrm{Me}-\mathrm{Bz}$ and $\mathrm{P}(\mathrm{Py}-\mathrm{EO})$ were firmly formed in the mixture of $\mathrm{P}(\mathrm{Py}-\mathrm{EO}) / 8 \mathrm{Az} 4 \mathrm{Me}-\mathrm{Bz}$ films, and the $\mathrm{Az}$ unit was introduced as the side chain of $\mathrm{P}(\mathrm{Py}-\mathrm{EO})$ at all temperatures under investigation.

X-ray scattering measurements were further conducted (Figure 3). At $100{ }^{\circ} \mathrm{C}$ and $115{ }^{\circ} \mathrm{C}, \mathrm{X}$-ray scattering was observed at $2 \theta=2.2^{\circ}$ corresponding to a spacing $(d)$ of $4.1 \mathrm{~nm}$. This value should be ascribed to the layer structure of side chain of $8 \mathrm{Az} 4 \mathrm{Me}-\mathrm{Bz}$. This layer structure disappeared in the isotropic state at $135^{\circ} \mathrm{C}$. At lower temperatures at $25^{\circ} \mathrm{C}$ and $50{ }^{\circ} \mathrm{C}$, a broad scattering was observed at $2 \theta=0.68^{\circ}(d=13.5 \mathrm{~nm})$. We did not elucidate yet the origin of this larger-scaled regular structure. 

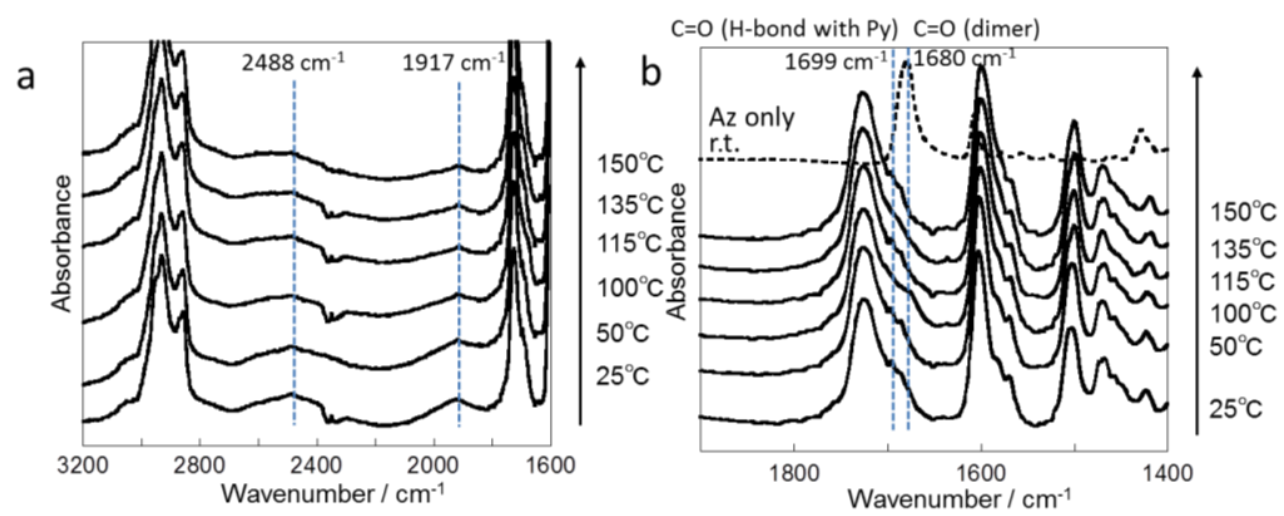

Figure 2. FTIR spectra of $\mathrm{P}(\mathrm{Py}-\mathrm{EO}) / 8 \mathrm{Az} 4 \mathrm{Me}-\mathrm{Bz}$ films in $1600-3200 \mathrm{~cm}^{-1}$ (a) and 1400-1900 $\mathrm{cm}^{-1}$ (b) regions at various temperatures. In (b), a spectrum of pure $8 \mathrm{Az} 4 \mathrm{Me}-\mathrm{Bz}$ film is included as a dashed line.

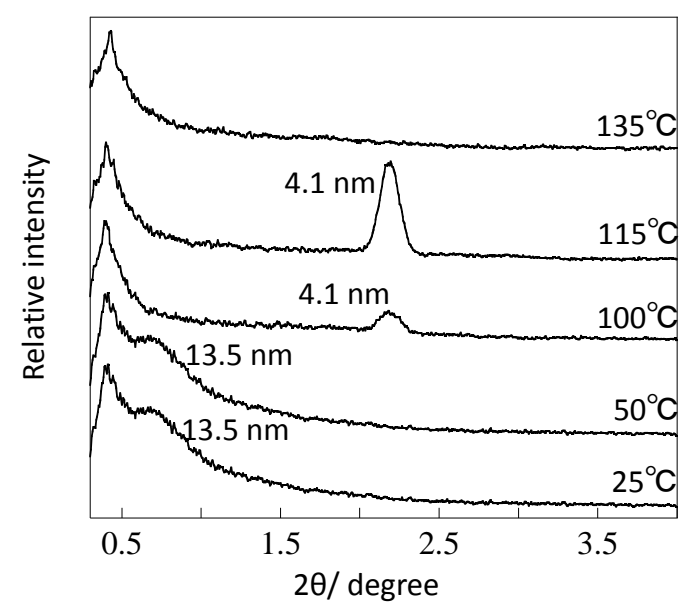

Figure 3. X-ray scattering profiles of $\mathrm{P}(\mathrm{Py}-\mathrm{EO}) / 8 \mathrm{Az} 4 \mathrm{Me}-\mathrm{Bz}$ at various temperatures.

\subsection{SRG Inscription and Replacement of Mesogens}

The strategy of this work using $\mathrm{P}(\mathrm{Py}-\mathrm{EO}) / 8 \mathrm{Az} 4 \mathrm{Me}-\mathrm{Bz}$ is depicted in Scheme 2. After an SRG structure is inscribed by irradiation with patterned UV light, crosslinking (fixation) of the SRG structure (Process A), removal (dissolving) of the Az mesogen by washing with a suitable solvent (Process B), and finally filling with another mesogen, cyanobiphenyl (CB) unit will be introduced (Process C). More details of the procedures of crosslinking and stuffing the SRG film are displayed in Scheme 3. Both chemical $[10,12]$ and photochemical [26] crosslinking may be achieved for the SRG fixation. In this study, chemical crosslinking was adopted using a formaldehyde vapor to undergo the acetal condensation between two hydroxyl groups in the $\mathrm{P}(\mathrm{Py}-\mathrm{EO})$ polymer (a). In the process of filling with $\mathrm{CB}$ unit, the free pyridine unit after the removal of $8 \mathrm{Az} 4 \mathrm{Me}-\mathrm{Bz}$ was reacted with $\mathrm{CB}-\mathrm{Br}$ (see Scheme 1) by the quarternization (b).

Figure 4a shows a time-course profile of the height difference between the top and bottom levels of the SRG structure upon irradiation with line-and-space $(10 \times 10 \mu \mathrm{m})$ patterned non-polarized UV light $\left(365 \mathrm{~nm}, 2 \mathrm{~mW} \cdot \mathrm{cm}^{-2}\right)$. Figure $4 \mathrm{~b}, \mathrm{c}$ shows AFM images and surface profiles after UV irradiation for $100 \mathrm{~s}$ and $1000 \mathrm{~s}$, respectively. An induction time was observed until $100 \mathrm{~s}$, and after this period, the SRG undulation was efficiently formed until $600 \mathrm{~s}$. The height difference reached $160 \mathrm{~nm}$ at $1000 \mathrm{~s}$, which corresponds to twice the thickness of the initial flat film $(85 \mathrm{~nm})$. The bottom area almost reached the level of substrate. In this way, very efficient mass migration occurred in this supramolecular film. The efficiency of the motion is comparable with that reported previously for relevant systems of 
covalently side chain films $[10,12]$. Sufficient mass transfer was observed around $1 \mathrm{~J} \cdot \mathrm{cm}^{-2}$. The motion was directed from un-irradiated areas to irradiated ones (supporting information), which agreed with the previous observations using covalently bonded Az side chains [11].

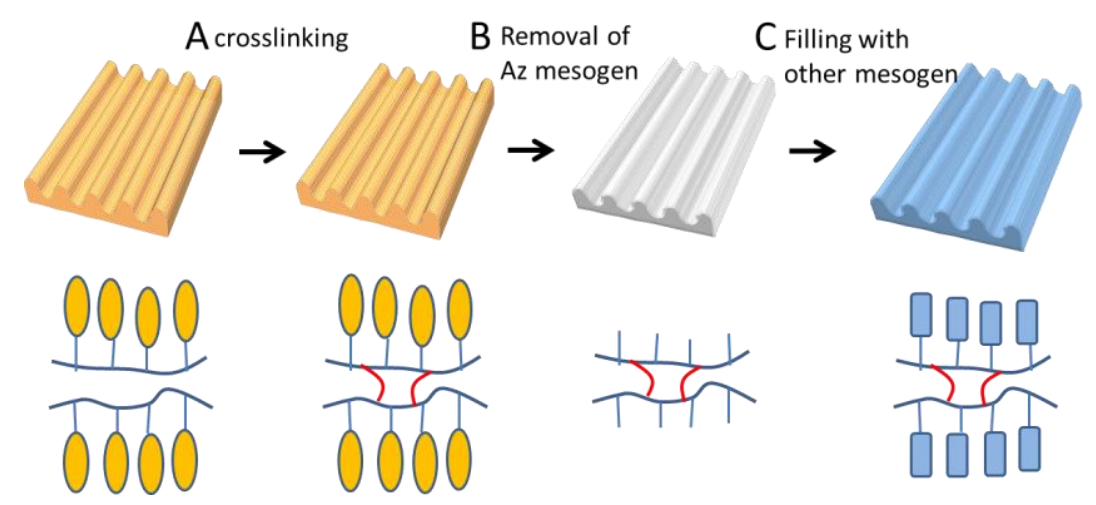

Scheme 2. Strategic scheme of the overall process in this work. Process A: chemical crosslinking (acetal formation) of polymer backbone in SRG-inscribed film; Process B: removal of hydrogen-bonded Az side chain by rinsing with a solvent; Process $\mathrm{C}$ : filling with $\mathrm{CB}$ derivative (CB-Br) by a chemical reaction.

a

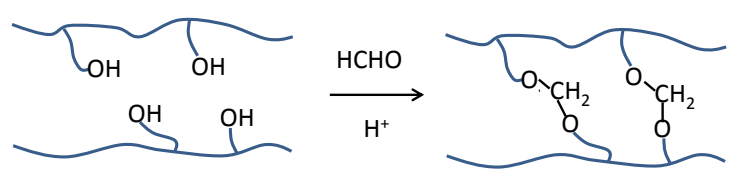

b

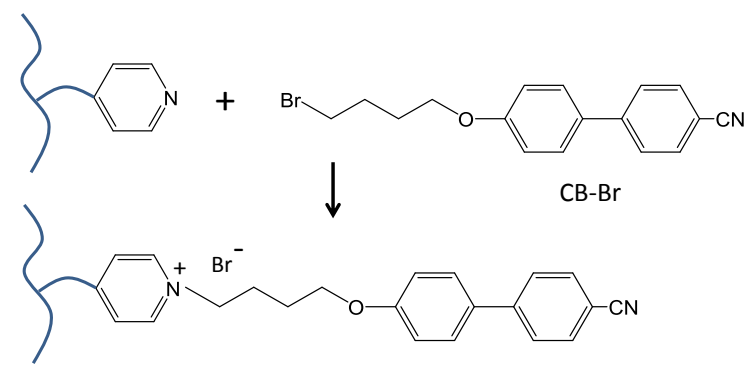

Scheme 3. Schematic illustrations of chemical crosslinking between two hydroxyl groups of oligo(ethylene oxide) side chain of $\mathrm{P}(\mathrm{Py}-\mathrm{EO})$ with formaldehyde ((a), Process B in Scheme 2), and reconstitution with a $\mathrm{CB}$ compound $(\mathrm{CB}-\mathrm{Br})$ by the quarternization reaction in the hollow $\mathrm{P}(\mathrm{Py}-\mathrm{EO})$ film ((b), Process C in Scheme 2).

The chemical crosslinking was achieved by exposure to a mixed vapor of formaldehyde and hydrochloride. The SRG-inscribed film was placed into a sealed container together with a hydrochloric acid $\left(6 \mathrm{~mol} \cdot \mathrm{L}^{-1}\right)$ and $30 \%$ (by weight) formaldehyde aqueous solutions for $1 \mathrm{~h}$. After this treatment, the SRG film was immersed in pure water to remove the unreacted reagents, and dried in a reduced pressure. Figure 5 indicates AFM images taken before (a) and after (b) the above treatment. As shown, the film surface of SRG became quite coarse (b); however, the height and periodic features was essentially unchanged as indicated in the surface profiles (c).

The sample treated as above was then immersed into tetrahydrofuran (THF) several times. Figure 6 shows the AFM images before (a) and after (b) the THF immersion. After the immersion into THF, the top-to-bottom height difference was reduced to approximately half from $164 \mathrm{~nm}$ to $87 \mathrm{~nm}$ (c). UV-visible absorption spectra revealed that the $\pi \pi^{*}$ band around $350 \mathrm{~nm}$ entirely disappeared after rinsing with this solvent $(\mathrm{d})$. These results clearly indicate that the initial side chain of $8 \mathrm{Az} 4 \mathrm{Me}-\mathrm{Bz}$ 
was fully detached from the crosslinked SRG-inscribed film. The chemical crosslinking between the hydroxyl groups was essentially needed for this process because both $8 \mathrm{Az} 4 \mathrm{Me}-\mathrm{Bz}$ and $\mathrm{P}(\mathrm{Py}-\mathrm{EO})$ were well dissolved in THF. The retained SRG structure (b) clearly shows that the film became insoluble to THF due to the formation of cross-linked chemical networks.

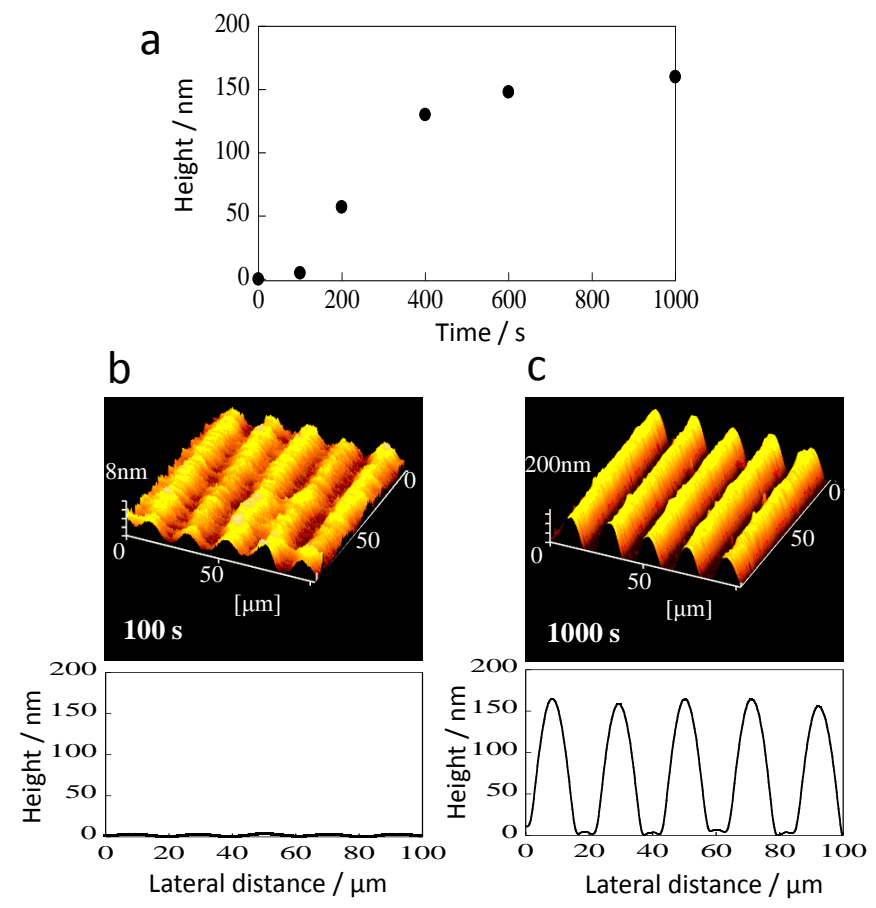

Figure 4. SRG formation of a $\mathrm{P}(\mathrm{Py}-\mathrm{EO}) / 8 \mathrm{Az} 4 \mathrm{Me}-\mathrm{Bz}$ film (initial thickness, $85 \mathrm{~nm}$ ). Time-course profile of height difference in the SRG formation process during UV $(365 \mathrm{~nm})$ light irradiation through a $10 \times 10 \mu \mathrm{m}$ line-and-space photomask at $2 \mathrm{~mW} \cdot \mathrm{cm}^{-2}$ and $120^{\circ} \mathrm{C}(\mathbf{a})$; and resulting AFM images after $100 \mathrm{~s}(\mathbf{b})$ and $1000 \mathrm{~s}(\mathbf{c})$.

a

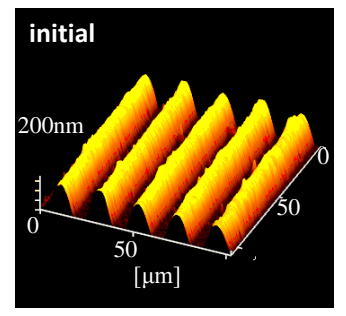

b

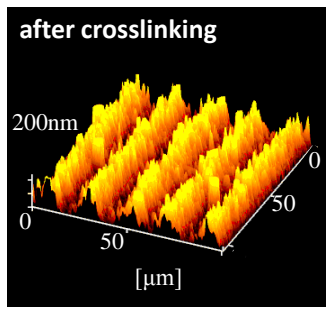

C

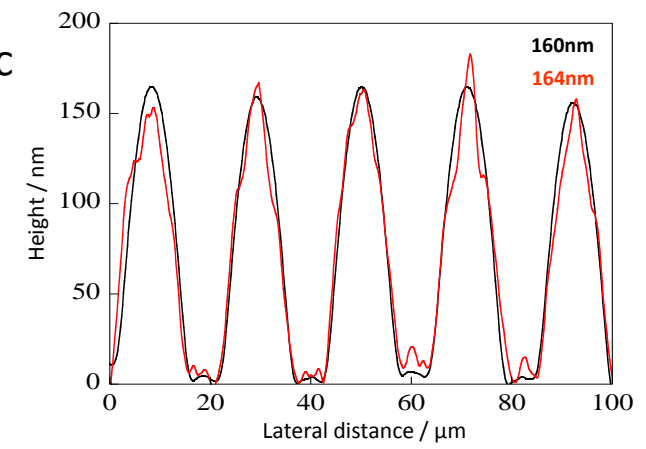

Figure 5. Chemical crosslinking (Process A in Scheme 2). AFM images before (a) and after (b) the acetal formation, and their surface profiles (c). 
a
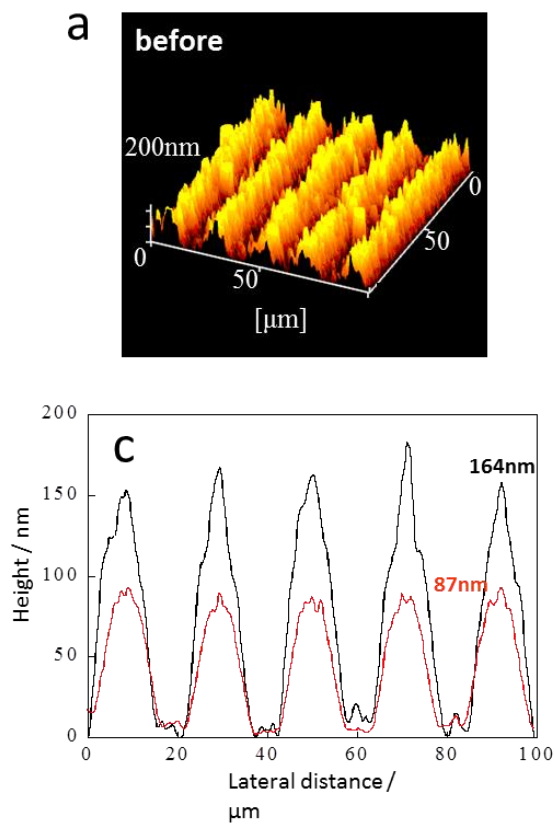

b after removal of $A z$
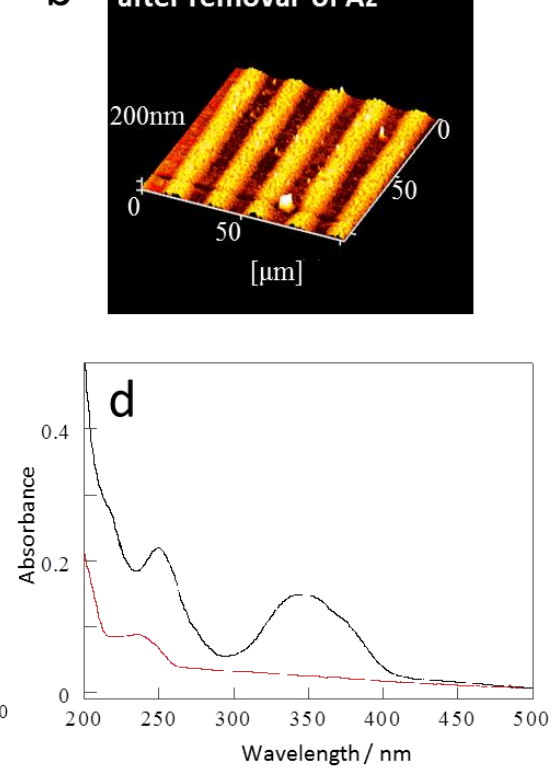

Figure 6. Removal of hydrogen-bonded Az side chain (Process B in Scheme 2). AFM images before (a) and after (b) washing with THF; surface profiles (c); and UV-visible absorption spectra (d) before (black) and after (red) the rinsing procedure.

Having these results, we next attempted to undergo a reaction with the free pyridine moiety of the crosslinked hollow $\mathrm{P}(\mathrm{Py}-\mathrm{EO})$ with $\mathrm{CB}-\mathrm{Br}$ by the quarternization reaction. The Az-free SRG film was immersed in a THF solution containing $\mathrm{CB}-\mathrm{Br}$ at the boiling temperature $\left(66^{\circ} \mathrm{C}\right)$ for 5 days. After this procedure, this sample was immersed into pure THF several times to remove unreacted CB-Br. Then, the resulting film was subjected to measurements of UV-visible absorptions and AFM.

In Figure 7, AFM images before (a) and after (b) the quarternization reaction are displayed. The height was slightly increased by the attachment of CB mesogen. The surface profile (c) indicates that $10 \%-20 \%$ increase of the height difference. The UV-visible absorption spectra (Figure $7 \mathrm{~d}$ ) indicated that the $\pi \pi^{*}$ band around $300 \mathrm{~nm}$ appeared after the reaction (red line). The CB group was actually reacted with the pyridine moiety and introduced to the crosslinked hollow $\mathrm{P}(\mathrm{Py}-\mathrm{EO})$ matrix. However, the recovery of the height difference was obviously insufficient. In this way, the strategy of the stuffing process was partly successful but not satisfactorily at the present stage. The molar extinction coefficients of $\mathrm{Az}$ and $\mathrm{CB}$ compounds employed were comparable, $3.0 \times 10^{4} \mathrm{~L} \cdot \mathrm{mol}^{-1} \cdot \mathrm{cm}^{-1}$ at $352 \mathrm{~m}$ and $2.5 \times 10^{4} \mathrm{~L} \cdot \mathrm{mol}^{-1} \cdot \mathrm{cm}^{-1}$ at $298 \mathrm{~nm}$, respectively. A recovery amount of mesogen can be roughly estimated by comparing the absorption spectra in Figures $6 \mathrm{~d}$ and $7 \mathrm{~d}$. Seemingly, approximately a half amount of mesogens was reconstituted in the quarternization process, although the height recovery ratio was apparently less, only by $10 \%-20 \%$. This discrepancy may be ascribed to the difference in the molecular orientation of mesogens. In the initial Az-containing film, the mesogens are oriented homeotropically to some extent. A reduced intensity of the $\pi \pi^{*}$ band of Az around $350 \mathrm{~nm}$ relative to that at $250 \mathrm{~nm}$ (Figure 6d, black line) indicates the tendency of homeotropic orientation [15]. The stuffing with CB by the chemical reaction in solvent may reduce the molecular packing and disturb the mesogen orientation, providing larger absorbance. The reasons for the insufficient reactivity of CB-Br with the pyridine residues could be ascribed to (i) the formation of denser crosslinking at the surface area that inhibits the penetration of $\mathrm{CB}-\mathrm{Br}$; and (ii) the existence of buried pyridine residues that repels the access of CB-Br. We expect that the optimization of the crosslinking conditions, reaction solvent, and conditions for the quarternization process will improve the recovery ratio in the mesogen stuffing. 
a
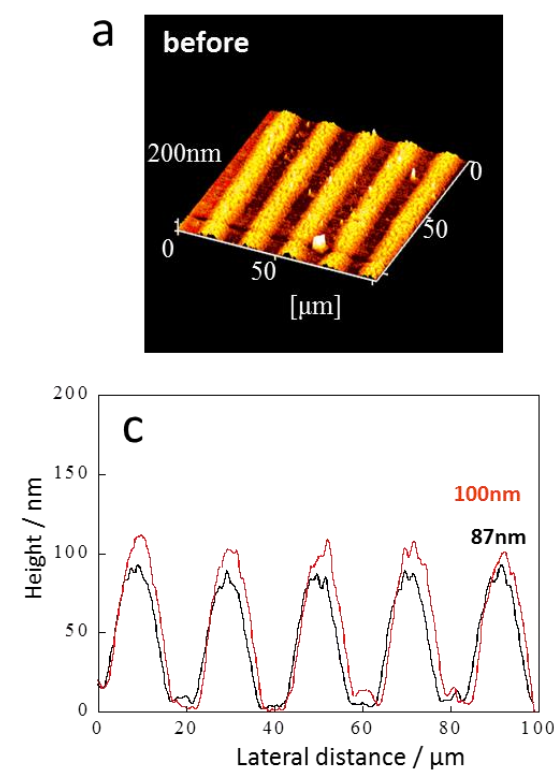
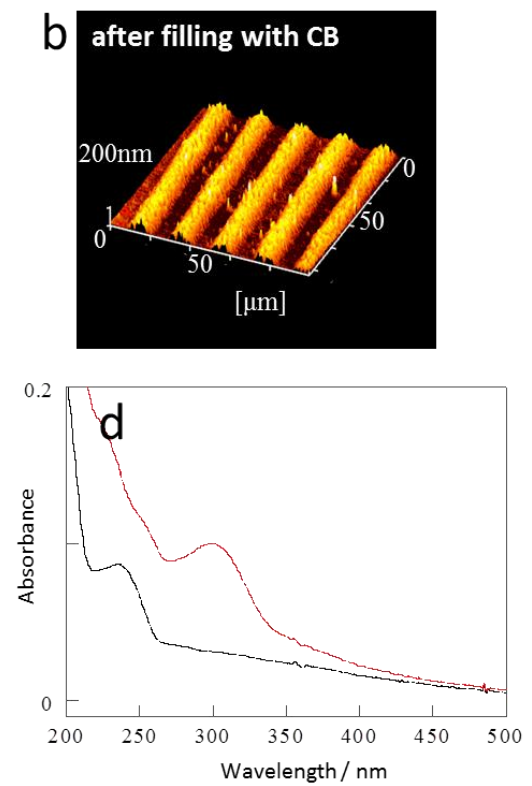

Figure 7. Filling with $\mathrm{CB}$ derivative (Process $\mathrm{C}$ in Scheme 2) into the hollow $\mathrm{P}(\mathrm{Py}-\mathrm{EO})$ matrix. AFM images before (a) and after (b) filling with the CB derivative, surface profiles ((c), black and red lines correspond to the profile before and after the reaction with $\mathrm{CB}-\mathrm{Br}$ ); and $\mathrm{UV}$-visible absorption spectra (d) before (black) and after (red) filling with CB.

\section{Materials and Methods}

\subsection{Materials}

Sodium hydroxide, potassium carbonate, triethylamine, AIBN was purchased from Kanto Chemicals. 6-Bromo-1-hexyanol, 1,4-dibromobutane, and methacryloyl chloride were obtained from TCI. Potassium iodide was purchased from Koso Chemicals. The reagents were used as received. THF and DMF were purified by distillation. A methacrylate monomer containing oligo(ethylene oxide) (PE200, unit $n=4.5$ on average) was kindly provided from NOF Corp.

The number-averaged molecular weight $\left(M_{n}\right)$ and polydispersity index $\left(M_{\mathrm{W}} / M_{\mathrm{n}}\right)$ were determined by gel permeation chromatography (GPC) using Shodex DS-4 (UV detector) with columns of KF 803F and KF 805L (eluent solvent: THF). $M_{\mathrm{n}}$ and $M_{\mathrm{w}} / M_{\mathrm{n}} \mathrm{P}$ (Py-EO) used in this work were found to be $8.9 \times 10^{3}$ and 1.24 , respectively. The content of pyridine unit in the resulting copolymer was determined by ${ }^{1} \mathrm{H}-\mathrm{NMR}$ using a JNM-GSX270 (JEOL). The copolymerization ratio of pyridine used in this work was 0.48 . The detailed synthetic procedures and characterizations are described in the supporting information.

\subsection{Methods and Measurements}

$\mathrm{P}(\mathrm{Py}-\mathrm{EO})$ and $8 \mathrm{Az} 4 \mathrm{Me}-\mathrm{Bz}$ was dissolved and mixed at a 1:1 (Py/Az) ratio in THF and slowly evaporated at $60^{\circ} \mathrm{C}$ to obtain a complexed powder. Polymer films were obtained by spincasting at $2000 \mathrm{rpm}$ for $30 \mathrm{~s}$ from a THF solution. The photo-triggered mass transfer was induced by UV ( $365 \mathrm{~nm})$ light irradiation through a $10 \times 10 \mu \mathrm{m}$ line-and-space photomask at $120^{\circ} \mathrm{C}$. UV light irradiation was performed with a Supercure-203S (Sanei Electronic) passing through combinations of Toshiba optical filters, UV35 and V44, for $365 \mathrm{~nm}$. Detailed procedures are described in the supporting information. Non-polarized light was used for the induction of SRG.

UV-visible absorption spectra were taken on an Agilent 8453 diode array spectrometer. Fourier transform infrared (FTIR) spectra were taken on a FTS 6000 (Biorad) with a DTGS detector. The resolution was $4 \mathrm{~cm}^{-1}$. DSC measurements were carried out with a DSC 200 (Seiko Instrument). The surface morphology was evaluated by AFM using a Nanopics 2100 (Seiko Instruments) equipped 
with a DMS/SS mode cantilever (NPX1CT004). X-ray analyses were performed with a NANO Viewer (Rigaku) using a $\mathrm{Cu} \mathrm{K} \alpha$ beam. POM observations were made using a BX-51 (Olympus).

\section{Conclusions}

In this work, we proposed a new strategy for replacement of mesogens in SRG-inscribed SCLCP films. In this process, the light responsive hydrogen-bonded Az mesogen that is able to induce the mass migration is replaced to a light-inert $C B$ side chain in the supramolecular framework. The fixing procedure (crosslinking) of the SRG-inscribed film was needed before the removal of the Az mesogen. The replacement of the mesogen is substantially advantageous in that a deeply colored SRG film can be turned to a transparent one at visible light wavelength regions. The complete removal of the $\mathrm{Az}$ mesogen was achieved; however, the satisfactorily filling to the hollow film was not satisfactorily performed under the conditions employed. Further effort is needed for optimizing the process conditions. Nevertheless, we believe that the present strategic proposal provides new possibilities in the fabrication and modifications of SRG-inscribed polymer thin films for the applications to optical devices and liquid crystal alignment.

Supplementary Materials: The following are available online at http:/ /www.mdpi.com/2073-4352/7/2/52/s1, Synthesis of materials: Figure S1: ${ }^{1} \mathrm{H}-\mathrm{NMR}$ spectra of Az derivatives, Figure S2: ${ }^{1} \mathrm{H}-\mathrm{NMR}$ spectra of pyridine derivatives, Figure S3: Illustration of irradiation setup, Figure S4: AFM image of a P(Py-EO)/8Az4Me-BA film irradiated with a patterned photomask, Figure S5: POM images of a P(Py-EO)/8Az4Me-BA film.

Acknowledgments: This work was supported by JSPS KAKENHI Grant Number JP15H01084 in Scientific Research on Innovative Areas (Photosynergetics), JSPS KAKENHI Grant Number JP16H06355 and JP15K13784 in Basic Scientific Research, and the Toyo Gosei Memorial Foundation

Author Contributions: Takahiro Seki and Shusaku Nagano conceived and designed the experiments; Shun Mitsui performed the experiments; Shusaku Nagano and Mitsuo Hara analyzed the data; Takahiro Seki wrote the paper.

Conflicts of Interest: The authors declare no conflict of interest.

\section{References}

1. Yager, K.G.; Barrett, C.J. All-optical patterning of azo polymer films. Curr. Opin. Solid State Mater. Sci. 2001, 5, 487-494. [CrossRef]

2. Natansohn, A.; Rochon, P. Photoinduced Motions in Azo-Containing Polymers. Chem. Rev. 2002, 102, 4139-4176. [CrossRef] [PubMed]

3. Viswanathan, K.N.; Kim, D.Y.; Bian, S.; Williams, J.; Liu, W.; Li, L.; Samuelson, L.; Kumar, J.; Tripathy, K.S. Surface relief structures on azo polymer films. J. Mater. Chem. 1999, 9, 1941-1955. [CrossRef]

4. Lee, S.; Kang, H.S.; Park, J.K. Directional photofluidization lithography: Micro/nanostructural evolution by photofluidic motions of azobenzene materials. Adv. Mater. 2012, 24, 2069-2103. [CrossRef] [PubMed]

5. Shimamura, A.; Priimagi, A.; Mamiya, J.; Ikeda, T.; Yu, Y.; Barrett, C.J.; Shishido, A. Simultaneous analysis of optical and mechanical properties of cross-linked azobenzene-containing liquid-crystalline polymer films. ACS Appl. Mater. Interfaces 2011, 3, 4190-4196. [CrossRef] [PubMed]

6. Seki, T. Meso- and Microscopic Motions in Photoresponsive Liquid Crystalline Polymer Films. Macromol. Rapid Commun. 2014, 35, 271-290. [CrossRef] [PubMed]

7. Seki, T. Photoresponsive self-assembly motions in polymer thin films. Curr. Opin. Solid State Mater. Sci. 2006, 10, 241-248. [CrossRef]

8. Kawatsuki, N.; Hasegawa, T.; Ono, H.; Tamoto, T. Formation of Polarization Gratings and Surface Relief Gratings in Photocrosslinkable Polymer Liquid Crystals by Polarization Holography. Adv. Mater. 2003, 15, 991-994. [CrossRef]

9. Ubukata, T.; Seki, T.; Ichimura, K. Surface Relief Gratings in Host-Guest Supramolecular Materials. Adv. Mater. 2000, 12, 1675-1678. [CrossRef]

10. Zettsu, N.; Ubukata, T.; Seki, T.; Ichimura, K. Soft Crosslinkable Azo Polymer for Rapid Surface Relief Formation and Persistent Fixation. Adv. Mater. 2001, 13, 1693-1697. [CrossRef]

11. Isayama, J.; Nagano, S.; Seki, T. Phototriggered Mass Migrating Motions in Liquid Crystalline Azobenzene Polymer Films with Systematically Varied Thermal Properties. Macromolecules 2010, 43, 4105-4112. [CrossRef] 
12. Zettsu, N.; Seki, T. Highly Efficient Photogeneration of Surface Relief Structure and Its Immobilization in Cross-Linkable Liquid Crystalline Azobenzene Polymers. Macromolecules 2004, 37, 8692-8698. [CrossRef]

13. Nakano, H.; Takahashi, T.; Kadota, T.; Shirota, Y. Formation of a Surface Relief Grating Using a Novel Azobenzene-Based Photochromic Amorphous Molecular Material. Adv. Mater. 2002, 14, 1157-1160. [CrossRef]

14. Ando, H.; Tanino, T.; Nakano, H.; Shirota, Y. Photoinduced surface relief grating formation using new polymers containing the same azobenzene chromophore as a photochoromic amorphous molecular material. Mater. Chem. Phys. 2009, 113, 376-381. [CrossRef]

15. Zettsu, N.; Ogasawara, T.; Arakawa, R.; Nagano, S.; Ubukata, T.; Seki, T. Highly Photosensitive Surface Relief Gratings Formation in a Liquid Crystalline Azobenzene Polymer: New Implications for the Migration Process. Macromolecules 2007, 40, 4607-4613. [CrossRef]

16. Yu, H.; Ikeda, T. Photocontrollable liquid-crystalline actuators. Adv. Mater. 2011, 23, 2149-2180. [CrossRef] [PubMed]

17. Seki, T. Light-directed alignment, surface morphing and related processes: recent trends. J. Mater. Chem. C 2016, 4, 7895-7910. [CrossRef]

18. Zettsu, N.; Ogasawara, T.; Mizoshita, N.; Nagano, S.; Seki, T. Photo-Triggered Surface Relief Grating Formation in Supramolecular Liquid Crystalline Polymer Systems with Detachable Azobenzene Unit. Adv. Mater. 2008, 20, 516-521. [CrossRef]

19. Goldenberg, L.M.; Kulikovsky, L.; Kulikovska, O.; Stumpe, J. New materials with detachable azobenzene: effective, colourless and extremely stable surface relief gratings. J. Mater. Chem. 2009, 19, 8068-8071. [CrossRef]

20. Nishizawa, K.; Nagano, S.; Seki, T. Micropatterning of titanium oxide film via phototactic mass transport. J. Mater. Chem. 2009, 19, 7191-7194. [CrossRef]

21. Kato, T.; Frechet, J.M.J. A new approach to mesophase stabilization through hydrogen bonding molecular interactions in binary mixtures. J. Am. Chem. Soc. 1989, 111, 8533-8534. [CrossRef]

22. Kato, T.; Frechet, J.M.J. Stabilization of a liquid-crystalline phase through noncovalent interaction with a polymer side chain. Macromolecules 1989, 22, 3818-3819. [CrossRef]

23. Kato, T.; Mizoshita, N.; Kanie, K. Hydrogen-Bonded Liquid Crystalline Materials: Supramolecular Polymeric Assembly and the Induction of Dynamic Function. Macromol. Rapid Commun. 2001, 22, 797-814. [CrossRef]

24. Kato, T.; Mizoshita, N.; Kishimoto, K. Functional Liquid-Crystalline Assemblies: Self-Organized Soft Materials. Angew. Chem. Int. Ed. 2006, 45, 38-68. [CrossRef] [PubMed]

25. Ambrožič, G.; Žigon, M. Hydrogen-bonded polyurethane complexes based on 4-alkoxybenzoic acids as the low molar mass components. Polym. Int. 2005, 54, 606-613. [CrossRef]

26. Li, W.; Nagano, S.; Seki, T. Photo-crosslinkable liquid-crystalline azo-polymer for surface relief gratings and persistent fixation. New J. Chem. 2009, 33, 1343-1348. [CrossRef] 